\title{
A família e a prática de amamentação em bebês de baixo peso ao nascer
}

\author{
The family and the practice of breastfeeding for low birth weight babies
}

La familia y la práctica de amamantar bebés de bajo peso al nacer

Laise Conceição Caetano ${ }^{\text {I }}$, Gabriela Santos Nascimento ${ }^{\mathrm{II}}$, Maria Cristina Aranha do Nascimento ${ }^{\mathrm{II}}$

\section{RESUMO}

Estudo prospectivo relativo ao acompanhamento de famílias em ambiente hospitalar e ambulatorial cujos bebês nasceram com baixo peso. Teve como objetivo de identificar fontes de apoio e conflito que influenciam o cuidado e a prática da amamentação, com base na estrutura das famílias e suas relações. Participaram do estudo 33 famílias com base no estudo do genograma, do ecomapa e das informações de protocolo estruturado. Utilizou-se como referencial teórico o Interacionismo Simbólico. Das famílias, 24,2\% tinham conflito intrafamiliar e ausência de apoio para o cuidado e amamentação. Tal condição se relacionou com dificuldades maternas cujo motivo predominante foi a condição emocional. Com o apoio das famílias, $40 \%$ das nutrizes tiveram dificuldades relacionadas ao manejo da amamentação. A amamentação exclusiva foi possível pelo diagnóstico das condições familiares, bem como da condição de suporte encontrada. A identificação dos pontos vulneráveis e o atendimento das necessidades dos familiares devem fazer parte dos cuidados.

Descritores: Relações Familiares; Aleitamento materno; Recém-Nascido; Comportamento Materno; Enfermagem Familiar.

\section{ABSTRACT}

This prospective study following up families at the hospital or in outpatient settings whose babies was born on low weight. The aim of the study was to identify the sources of support and conflict that influenced care and breastfeeding practices, based on family structures and its relationships. Data were collected from 33 families based in genograms, ecomaps and information from a structured protocol. The Symbolic Interactionism was the theoretical reference. Among the families, $24.2 \%$ had conflicts within the family and a lack of support for care and breastfeeding. This condition correlated with maternal difficulties, predominantly of emotional nature. With family support, $40 \%$ of the breastfeeding women had difficulties relating to management of breastfeeding. The exclusive breastfeeding was possible in accordance with the diagnosis of family conditions and the support conditions encountered. The vulnerable points identification as health assistance to familiars has to be considered in health care.

Descriptors: Family Relationships; Breast Feeding; Infant, Newborn; Maternal Behavior; Family Nursing.

\section{RESUMEN}

Estudio prospectivo referente al seguimiento de familias en ambiente hospitalario y ambulatorio, cuyos bebés nascieron con bajo peso. El objetivo fue identificas fuentes de apoyo y conflicto que influyen en el cuidado y práctica de amamantar, con base en la estructura de las familias y sus relaciones. Datos fueron recogidos con 33 familias, basado en genograma, ecomapa y informaciones en un protocolo estructurado. Se utilizó como referencial teórico el Interaccionismo Simbólico. De dichas familias, 24,2\% tenían conflicto intrafamiliar y ausencia de apoyo en el cuidado y para amamantar. Esta circunstancia se relacionó con dificultades maternas cuyo motivo principal fue la condición emocional. Con apoyo familiar, $40 \%$ de las nutrices tuvieron dificultades relacionadas con la práctica de amamantar. La amamantación exclusiva fue posible por el diagnóstico de las condiciones familiares, así como también de la condición de soporte encontrada. La identificación de los puntos vulnerables y la atención a las necesidades de los familiares deben hacer parte de la base de cuidados.

Descriptores: Relaciones Familiares; Lactancia Materna; Recién Nacido; Conducta Materna; Enfermería de la Familia.

\footnotetext{
${ }^{\mathrm{I}}$ Enfermeira, Doutora em Enfermagem em Saúde Pública. Professora Doutora, Escola de Enfermagem, Universidade Federal de Minas Gerais. Belo Horizonte, MG, Brasil. E-mail: laise13@yahoo.com.br.

II Enfermeira. Enfermeira do Programa Saúde da Família, Prefeitura de Contagem. Contagem, MG, Brasil. E-mail: gabinasci19@yahoo.com.br.

III Médica, Doutora em Ciências da Saúde. Professora Adjunta, Universidade Federal de Ouro Preto. Ouro Preto, MG, Brasil. E-mail: nascimen@globalsite.com.br.
} 


\section{INTRODUÇÃO}

Políticas de saúde tais como de atenção ao recémnascido prematuro por meio da Metodologia Canguru, dentre outras, têm priorizado a atenção à família, mudando o paradigma assistencial de enfoque exclusivo no indivíduo. Esse novo modelo tem permitido não só um aumento na qualidade da assistência, mas também a garantia de atenção humanizada. Assim, na atenção ao recém-nascido $(\mathrm{RN})$, tem-se buscado atender igualmente a sua família(1).

O nascimento de uma criança traz mudanças na vida dos membros da família, bem como, na dinâmica e no cotidiano familiar. Tais mudanças podem ser mais intensas quando a criança nasce em momentos não esperados e ou quando necessita de cuidados diferenciados pela condição de imaturidade. Pesquisas têm demonstrado a difícil trajetória das crianças e suas famílias na evolução pós-natal e também têm mostrado que o cuidado oferecido é fundamental para a criança e para os responsáveis por ela(2-5).

Muito embora, a nível hospitalar o neonato tenha suas demandas clínicas e de cuidado prontamente atendidas, no domicílio, os cuidados e, principalmente o manejo para com a alimentação da criança prematura, é um desafio para mãe e familiares; além disso, a adaptação às condições de vulnerabilidade que exige monitoramento contínuo para o crescimento e desenvolvimento associado a manutenção do estado de saúde vem exigir a implementação de ações e rotinas que não são comuns no dia a dia familiar e podem gerar situações de stress e impossibilidade de resolução imediata. Sendo assim a atenção à crianças imaturas e/ou de baixo peso ao nascer são desafios para a família e para a enfermagem na atenção domiciliar ${ }^{(6)}$.

Mas, apesar de reconhecer a presença dos desafios e considerar que a família está sempre inserida no contexto do cuidado, ela ainda é pouco reconhecida como o sujeito do cuidado; conforme preconiza a filosofia do cuidado centrado na família, o cuidado à saúde é um processo de atenção baseado em parceria, com benefícios mútuos entre pacientes, familiares e provedores. A enfermagem está entre as profissões da área da saúde que mais convive com a família. Para alcançar a atenção efetiva dos seus clientes obteve um avanço ao conceber a família como unidade do cuidado. $\mathrm{Na}$ atenção à criança foi considerado como a maneira de cuidar da criança e sua família assegurando que haja um planejamento em torno da família como unidade, nesse sentido todos os membros são reconhecidos como foco do cuidado e não somente a criança(7).

É necessário, portanto, a vigilância, a orientação e o suporte à família, não somente no ambiente hospitalar, mas também no cenário familiar, após a alta. A família é a principal cuidadora de seus membros e, especialmente, do novo membro, o recém-nascido. Porém, para que o cuidado seja efetivado, a família precisa também ser assistida. É preciso conhecê-la e acessar suas necessidades.

É essencial compreender a família como a mais constante unidade de saúde para seus membros. Assim, para a assistência à família como unidade de cuidado, faz-se necessário conhecer como cada uma cuida e identifica suas forças, suas dificuldades e seus esforços para partilhar as responsabilidades. Com base nas informações obtidas, os profissionais devem usar seus conhecimentos sobre cada família, para, junto dela, pensar e implementar a melhor assistência possível ${ }^{(7-8)}$.

Foi com esse objetivo que, por meio do projeto "O cuidado transicional do recém-nascido e família", desenvolvido em um hospital público de Belo Horizonte, foi efetuado um estudo sobre o papel da família no cuidado do RN prematuro e nascido a termo. A assistência oferecida, tanto no alojamento conjunto quanto no ambulatório, tem foco nos cuidados básicos com o bebê, como higiene, sono, cuidados com a pele, eliminações, amamentação, e no cuidado com a mãe e suas demandas no domicílio. Mas com o projeto, a equipe de saúde se aproximou dos familiares para favorecer o cuidado do recém-nascido e também dos outros componentes da família. Faz-se, inicialmente, uma avaliação da estrutura e das relações intrafamiliares para se construir, no âmbito doméstico, possibilidades de apoio e cuidado no que se refere à prática da amamentação.

É importante o apoio dos profissionais de saúde à família na evolução neonatal. Porém, o apoio intrafamiliar também deve ser considerado, pois a capacidade da família para cuidar de seus membros pode estar comprometida, diminuída ou ausente em determinadas situações ou fases de sua trajetória( ${ }^{(8-9)}$. É preciso, então, estar junto dela a fim de impulsioná-la para o alcance de seu equilíbrio e para descobrir estratégias que facilitem o desenvolvimento de suas tarefas e demandas diárias, sejam elas relacionadas ou não ao cuidado para a saúde.

Um aspecto relevante a ser mencionado na abordagem à família é a amamentação, já que há 
escassez de estudos acerca do caráter social e familiar da opção de amamentar bem como de sua continuidade após a alta hospitalar. A família tem um notável papel de influência para a decisão e a prática da amamentação, principalmente quando recebe um recém-nascido de baixo peso como seu novo membro. A família deve ser vista como parte integrante da experiência de amamentação e como meio de suporte e apoio à mãe e ao filho durante todo o processo da lactação ${ }^{(8)}$.

Com base nessas premissas, o presente estudo teve como objetivos analisar a estrutura das famílias e as relações entre seus membros destacando presença de apoio e de conflito para o cuidado com o recém-nascido de baixo peso ao nascer e identificar a influência das relações familiares na prática de amamentação dessas crianças.

\section{METODOLOGIA}

Trata-se de um estudo prospectivo e descritivo relativo ao acompanhamento à famílias realizado por meio do projeto de extensão denominado "O cuidado transicional do recém-nascido e família". O projeto tinha como objetivo assistir ao recém-nascido a termo e prétermo preparando a família para o cuidado no hospital e no domicílio, com destaque para os cuidados no manejo e alimentação dos bebês (início e continuidade do aleitamento materno). Foi realizado o acompanhamento de 43 famílias, inicialmente no período de internação logo após o parto e, depois, semanal ou quinzenalmente, no ambulatório de um hospital da cidade de Belo HorizonteMG, sendo que 40 recebiam recém-nascidos pré-termo e três recebiam bebês nascidos a termo.

O acompanhamento às famílias iniciou-se em 2007, mas, para a pesquisa foi considerado o período de maio a dezembro de 2009. No hospital, durante a internação, a abordagem à mãe e aos familiares iniciou-se por meio da observação e do diagnóstico das necessidades de cuidado e orientação. Nesse momento, confeccionaramse o genograma e o ecomapa das famílias e fez-se o registro das observações e necessidades encontradas.

No ambulatório, a partir da primeira consulta da criança, deu-se a continuidade da avaliação quanto ao cuidado e as condições do contexto familiar para cuidar. Mãe e familiares foram acompanhados até 40 semanas de idade gestacional corrigida para os prematuros ou até atender à necessidade pela qual se deu o encaminhamento do RN a termo e da família. Foi construído um protocolo para levantar informações acerca da identificação dos membros da família, suas relações e possibilidades de apoio além do diagnóstico de condição de cuidados por parte dos familiares. Foram incluídas todas as famílias que aceitaram participar do estudo por meio do Termo de Consentimento e que estavam dispostas a continuar com o acompanhamento para a atenção ambulatorial no hospital.

$O$ estudo da estrutura e das relações familiares foi feito por meio do genograma e do ecomapa. O uso desses instrumentos na avaliação estrutural da família auxilia positivamente, permitindo obter esse conhecimento de forma rápida, prática e confiável. Além da análise dos genogramas e dos ecomapas, informações complementares colhidas auxiliaram no estudo das famílias $^{(10)}$.

Enfermeiras canadenses idealizaram um modelo de avaliação e intervenção na família resultando em uma estrutura multidimensional, subdividida em três categorias relativas à família: 1) Estrutural - em que se deve saber quem faz parte da família; como se dá o relacionamento entre seus membros; quem se relaciona melhor com quem dentro da família; e como é o relacionamento da família com o meio; 2) Desenvolvimental - relativo ao processo de mudança estrutural e de transformação progressiva da história familiar durante as fases do ciclo familiar, com o registro das mudanças em sua constituição ao longo dos anos se têm ou não filhos, adotam, morrem, casam, divorciam-se, etc; isso permite formular hipóteses sobre as experiências e as dificuldades vividas anteriormente e, então, junto dela, propor ou descartar estratégias para a superação dos problemas a partir dessas experiências; 3) Funcional - indica o modo como os indivíduos geralmente se comportam em relação aos outros, possibilitando, assim, explorá-los sob duas perspectivas, uma relativa às atividades diárias e cotidianas (comer, dormir, divertir-se, tomar remédios, etc.), e outra relativa aos aspectos da comunicação verbal e não verbal entre os membros da família(10).

Para guiar o diagnóstico e o direcionamento dos cuidados de enfermagem, o presente estudo utilizou-se da primeira categoria, ou seja, a avaliação estrutural e os relacionamentos intrafamiliares. A análise dos dados utilizou como referencial teórico o Interacionismo Simbólico. A pesquisa foi autorizada pelo Parecer 145/2009 do CEPHOB (Comitê de Ética em Pesquisa do Hospital Odilon Behrens - BH/MG). 


\section{Os dados}

O estudo envolveu 43 famílias; porém, em 10 delas, não foi possível analisar todos os dados. Foram consideradas, então, as informações colhidas sobre 33 famílias. Dessa análise, consideraram-se a presença e a ausência de apoio para o cuidado, e a presença e a ausência de dificuldades para amamentar, conforme mostra a Tabela 1. As dificuldades mostraram-se relacionadas ao manejo da amamentação, definido como posicionamento ou pega incorreta do bebê ao seio, diminuição na produção de leite, mamadas noturnas e/ou tempo e frequência inadequados das mamadas. Já no Quadro 1, veem-se as repercussões do manejo da amamentação e do tipo de aleitamento das nutrizes em contexto familiar conflituoso.

Tabela 1: Nutrizes que receberam ou não apoio para amamentar e relação do apoio com presença ou ausência de dificuldade para a amamentação. Belo Horizonte, MG, 2009.

\begin{tabular}{cccc}
\hline \multicolumn{2}{c}{ Presença de Apoio } & Ausência de Apoio \\
\hline 25 nutrizes $(75,8 \%)$ & \multicolumn{3}{c}{ A nutrizes $(24,2 \%)$} \\
\hline \multicolumn{4}{c}{ Amamentação } \\
\hline Sem dificuldade & Com dificuldade & Sem dificuldade & Com dificuldade \\
15 nutrizes $(60 \%)$ & 10 nutrizes $(40 \%)$ & 3 nutrizes $(37,5 \%)$ & 5 nutrizes $(62,5 \%)$ \\
\hline
\end{tabular}

Quadro 1: Representação do manejo da amamentação e do tipo de aleitamento de sete nutrizes em contexto familiar conflituoso. Belo Horizonte, MG, 2009.

\begin{tabular}{|c|c|}
\hline Tipo de dificuldade no processo de amamentação & Tipo de aleitamento na alta ambulatorial \\
\hline Condição emocional & AM \\
\hline Condição emocional & LME \\
\hline Manejo & LME \\
\hline Condição emocional & LME \\
\hline Condição emocional & LME \\
\hline Condição emocional & AM \\
\hline LME: Leite Materno Exclusivo & AM: Aleitamento Misto
\end{tabular}

Observação: das nutrizes analisadas, apenas uma não apresentou dificuldade no processo de amamentação, apesar do contexto familiar conflituoso.

De acordo com a Tabela 1, das 33 nutrizes analisadas, 24,2\% não receberam nenhum tipo de apoio. $A$ ausência de apoio esteve relacionada às dificuldades no cuidado referente à amamentação, ligadas, principalmente, à condição dos RN's que, por serem em sua maioria prematuros (apenas três nasceram a termo), apresentavam-se em estado constante de sonolência, dificultando o momento da mamada.

Das 25 nutrizes que tiveram apoio, 40\% também apresentaram dificuldades, destacando-se o manejo para a amamentação. Tal condição é esperada, pois, amamentar uma criança prematura exige maior habilidade e preparo por parte da mãe, bem como ambiente familiar favorável. A tensão gerada, principalmente para o ganho de peso adequado, é constante para os familiares. Até o ganho de peso esperado, que é de $15 \mathrm{~g} / \mathrm{dia}$, o acompanhamento por parte da equipe de saúde é semanal. Devido ao acompanhamento oferecido antes e após a alta hospitalar, a grande maioria, ou seja, 27 bebês saíram em aleitamento materno exclusivo (AME). Os outros seis estavam, no momento da alta, em aleitamento misto.

No momento da alta ambulatorial, estudou-se o tipo de aleitamento e sua relação com a ausência e presença de apoio. Percebeu-se que a relação de apoio com aleitamento materno exclusivo não é significativa: $84 \%$ das mães apoiadas pela família tiveram alta em AME e $16 \%$ em aleitamento misto. Em contrapartida, ao receberem alta, $75 \%$ das nutrizes sem apoio também davam a seus bebês apenas o leite materno, e $25 \%$ os alimentavam com o aleitamento misto. Essa situação pode demonstrar que a questão do aleitamento materno perpassa o apoio familiar ou da equipe de saúde, pois é um processo complexo e não possui somente essa variável como determinante.

A possível repercussão das condições familiares pode ser visualizada no Quadro 1 que apresenta o resultado do processo de amamentação nas famílias em conflito. Apenas uma das nutrizes não apresentou dificuldade; porém foi considerada, por familiares, totalmente incapaz de cuidar do filho, o que a influenciou a não 
manter o aleitamento exclusivo. Todas as outras que enfrentaram conflito no ambiente familiar tiveram dificuldade no processo de amamentação, tendo por motivo predominante a condição emocional materna, caracterizada por insegurança, ansiedade, nervosismo, ausência do companheiro ou demanda excessiva de cuidados.

\section{DISCUSSÃO E ANÁLISE}

No estudo não foi possível estabelecer a relação apoio familiar/aleitamento materno exclusivo e ausência de apoio/aleitamento materno misto. O que se percebeu foi a presença de conflito como interferência negativa para o desenvolvimento do cuidado com o recémnascido, tendo destaque a amamentação.

Tem-se a predominância de famílias com RN prematuros e baixo peso ao nascer que necessitam de forma contundente do leite materno para sua evolução neonatal. Tal situação eleva, para a mãe, a responsabilidade pelo cuidado associada ao provimento, de forma adequada, da nutrição do filho. Ainda há de se considerar, na evolução de um bebê prematuro, que, na maioria das vezes, o mesmo não inicia facilmente a sucção direta na mama materna. Ele passa por um período de adaptação e desenvolvimento do reflexo de sucção, dependendo da idade gestacional ao nascer. Mais uma vez, a mãe deve manter a produção láctea sem a sucção direta do bebê, empreendendo uma trajetória de ações no domicílio e no hospital, de forma a garantir o conteúdo lácteo que atenda à necessidade do filho. Ainda no ambiente hospitalar, estudo acerca da alimentação de bebês baixo peso ao nascer aponta momentos difíceis para familiares quando do inicio da amamentação, uma vez que a criança não se adequa facilmente ao peito devido a boca muito pequena, dificuldade de pega na região mamilo areolar e demora da ejeção láctea(6).

Mas o leite materno para a vida do filho prematuro pode significar muito, e qualquer erro ou dificuldade pode comprometer as condições de vida do bebê, que, no nível familiar, pode se constituir como significadochave para a ação e a tomada de decisão quanto ao cuidado dessa criança ao nascer ${ }^{(9)}$. Associado a este, outro significado surge no cenário familiar; este provém da experiência vivida no parto e no pós-parto de uma criança pequena e de sua condição física e clínica após o nascimento; a vulnerabilidade e a fragilidade do filho que depende, ao nascer, de um aparato tecnológico complexo para viver pode direcionar as decisões e guiar as ações bem como os cuidados por parte da família(23,9).

Voltando a atenção para as famílias do estudo, a prematuridade ou o baixo peso ao nascer associado à condução dos pais para aleitar ou oferecer o leite humano permearam o período vivido por eles desde o hospital e após a alta. Daí, para a prática do cuidado, a atenção e as ações dos pais estavam voltadas para o aleitamento e a condição física e de saúde da criança.

O cuidado, por sua vez, constitui-se em ações e estratégias que a família desenvolve no viver cotidiano para promover a vida e a saúde de seus membros. Nesse processo, constroem significados, valores, práticas que, em parte, são oriundos de sua família de origem, de seu ambiente sociocultural e, em parte, do viver e do conviver com suas próprias experiências e interações intra e extra-familiares. A convivência, as reflexões e as interpretações que surgem em decorrência dessas interações, levam as famílias à compreensão da situação vivida que, por sua vez, direciona e define sua própria maneira de agir. Esse processo interpretativo da situação vivida que conduz a uma ação conjunta para o cuidado pode ser explicado sob a perspectiva do Interacionismo Simbólico, que concebe a sociedade como uma entidade de indivíduos ou grupos em interação tendo por base os sentidos ou significados que as coisas ou fatos têm para eles $^{(11-12)}$.

As ações e o apoio formalizam-se pela cooperação, pelo alinhamento de ações a fim de responder à necessidade do cuidado ${ }^{(12)}$. No domicílio, a presença de apoio para o cuidado da amamentação foi maior, mas as dificuldades para amamentar foram equivalentes entre as mães que tinham apoio e aquelas que não o tinham. Tal informação parece, a princípio, não ter significado para olhar as famílias e suas condições de cuidado, mas a natureza das dificuldades é distinta; para aquelas mães que tiveram apoio familiar, as dificuldades estavam ligadas a aspectos técnicos da amamentação (condição de pega, sucção lenta, oferecimento de leite humano pelo copo). Atribui-se tal condição ao apoio recebido, uma vez que os aspectos técnicos estão presentes também no ambiente hospitalar onde a mãe recebe ajuda e apoio da equipe de saúde. È preciso também considerar que o ato de amamentar é resultado de experiências individuais sendo marcado pelo ambiente de cada mulher, isso pode explicar o fato daquelas que, mesmo com ajuda e apoio, ainda apresentaram dificuldades no manejo da amamentação no domicílio ${ }^{(6,13)}$. 
Para aquelas que não tinham apoio, as dificuldades incidiram sobre as demandas do cuidado e sua relação com a condição de imaturidade do filho: a sonolência constante, o controle das mamadas sob livre demanda, principalmente à noite, produção de leite para atender a necessidade da criança e ainda a presença de tensão relacionada à efetividade de suas ações para a condição de crescimento e desenvolvimento da criança.

As ações e as interações estabelecidas entre os familiares criam significados que podem ser compartilhados ou não, resultando em ajustes ou desajustes. A falta de ajuste pode manifestar-se como desarmonia, sofrimento e até doença' As dificuldades ou até a ausência de interações entre membros, bem como os diferentes significados presentes no contexto familiar (ideias e opiniões divergentes) podem afetar o processo do cuidar $^{(10)}$. Quanto à amamentação e ao cuidado do bebê, nas famílias em estudo, nas sete que viviam relações de conflito, não havia concordância quanto à forma de alimentar a criança pelas características da prematuridade. Além disso, cinco mães apresentaram condição emocional alterada durante a internação e, após a alta hospitalar, quando, então, já se encontravam no ambiente familiar.

O pequeno número de famílias em desarmonia não oferece base para uma análise mais profunda. Mas os significados atribuídos à experiência vivida no parto, associados à evolução do bebê pequeno e à demanda de cuidado, podem ter interferido na condição materna que, no ambiente familiar, não obteve modificação. As discordâncias entre os familiares quanto ao cuidado do bebê, associadas à condição materna, podem ter gerado conflitos e desarmonia nas interações intrafamiliares, com interferência direta na atenção à criança. Em momentos da atenção ambulatorial foi necessário abordar familiares da nutriz como sogra, tia, irmã e até o esposo para esclarecimentos acerca da necessidade de adequação das ações relativas ao cuidado.

Ao apresentar condições especiais de saúde e necessitar de cuidados habituais modificados relacionados a alimentação, a família do bebê de baixo peso necessita aprender a manejar a sua forma de alimentação e não somente a mãe, além disso técnicas de alimentação como o uso do copinho são integrados aos hábitos e ao saber intergeracional de pessoas da família como as avós que apresentam estranhamentos e questionamentos, não só deste, mas de outros cuidados que não fazem parte do contexto cultural familiar. A influência de familiares no cuidado, principalmente no processo da amamentação pode levar até ao desmame precoce pelo conflito entre gerações permeadas por crenças, mitos e tabus que não estão em harmonia com as práticas específicas de atenção a bebês prematuros e/ou de baixo peso ao nascer ${ }^{(6,8,14)}$.

Os conflitos e/ou a ausência de apoio têm também, como consequência, a perda de autonomia do responsável pelo cuidado. No que diz respeito ao cuidado de um recém-nascido, o bebê demonstra fome ou saciedade e espera a resposta materna; a mãe, por sua vez, responde oferecendo alimentação (mama) como símbolo de conforto, aquecimento e nutrição do filho. $O$ cuidado e a amamentação são expectativas ou comportamentos esperados pela própria mãe e pelos outros membros da família. Porém, quando as expectativas não ocorrem conforme o esperado ou não atendem aos significados construídos pela família, a mãe pode sentir-se culpada e podem surgir conflitos e/ou perda de autonomia para o cuidado ${ }^{(15-16)}$.

Nas famílias estudadas, foi observada a perda de autonomia materna, o que levou a dificuldades para cuidar do filho e, mais especificamente, de alimentá-lo exclusivamente com leite materno. Outras condições encontradas no ambiente familiar como o excesso de demanda de cuidado no domicílio e a falta do companheiro indicaram déficits de interação, de harmonia familiar e de possíveis momentos de ajuda e apoio influenciando também na perda de autonomia materna. Análise de trabalhos científicos sobre a influência da rede social da lactante no contexto da amamentação mostra que esta rede que se constitui de hábitos, costumes, conjunto de relações que determinam a características da pessoa, somada a vulnerabilidade da mulher durante o processo da maternidade e lactação, exerce forte interferência na decisão de amamentar e até na continuidade da mesma. Tal interferência pode ocorrer por meio de diferentes âmbitos: estímulo, apoio, valores culturais e repasse de conhecimentos ou tradição familiar que leva ao desinteresse, ao desestímulo e a pressão exercida sobre a nutriz quanto a forma de alimentar a criança ${ }^{(13)}$.

A família é capaz de interferir positiva ou negativamente no processo vivido e a aproximação do profissional de saúde do ambiente materno faz-se necessária. O perfil dos bebês associado às condições que cercaram os cuidadores no ambiente familiar deve ser considerado para a assistência por parte do profissional de saúde. Além disso, é preciso destacar que a mulher é o membro da família em que se centralizam 
todos os cuidados e ações relativos ao bebê, principalmente a amamentação. Entre os fatores psicológicos que influenciam a duração da amamentação, estão a eficiência para o cuidado, o estresse, a confiança em sua capacidade para amamentar, a flexibilidade e a capacidade de adaptação maternas ${ }^{(15-16)}$. O cuidado familiar, no cotidiano, consiste em experiências rotineiras de domínio dos familiares, mas, em momentos especiais, essas diferem da rotina do dia a dia e podem levar ao estresse e a crises familiares. Como componentes do cuidado familiar, estão presentes a adaptação, o compromisso e a presença de seus membros para ouvir, dialogar, estar próximos, além de desenvolver conjuntamente ações relativas ao cuidado(17).

$\mathrm{O}$ acompanhamento da equipe perdurou até a idade de 40 semanas de idade corrigida da criança. A perspectiva do Interacionismo foi fundamental para mostrar o que era significativo observar, encontrar os significados e relacioná-los com as ações familiares além de oferecer subsídios para refletir e interpretar o que estava vivenciando a família. O Interacionismo associado à avaliação da família(10-12) guiou as ações dos profissionais, auxiliou a identificar os déficits de interação, a ausência e existência de fontes de apoio intrafamiliar, a identificação das fragilidades, além de oferecer subsídios para orientar as ações de acordo com as possibilidades de cada família, as transformações e adaptações para a atenção do RN e para o atendimento das demandas de cuidado no domicílio. Desta maneira, todas as mulheres estudadas, apesar das dificuldades e dos conflitos em algumas famílias, permaneceram com a amamentação, ainda que mista. A atenção no período pós-parto possibilitou-lhes ser flexíveis e adaptar-se à situação vivida, tendo ainda confiança em si e em sua capacidade de cuidar do filho.

\section{CONSIDERAÇÕES FINAIS}

Para prestar assistência, a enfermagem deve ter a família como unidade de cuidado, sendo assim é necessário construir estratégias ou métodos que

\section{REFERÊNCIAS}

1. Furtado MCC, Mello DF, Parada CMGL, Pinto IC, Reis MCG, Scochi CGS. Avaliação da atenção ao recém-nascido na articulação entre maternidade e rede básica de saúde. Rev. Eletr. Enf. [Internet]. 2010 [cited 2011 set 30];2(4): 640-6. Available from: http://www.fen.ufg.br/revista/v12/n4/pdf/v12n4a07.pdf.

2. Souza NL, Araújo ACPF, Azevedo GD, Jerônimo SMB, Barbosa LM, Sousa NML. Percepção materna com o nascimento prematuro e vivência da gravidez com pré-eclampsia. Rev Saude Publica [Internet]. 2007 [cited 2011 set 30];41(5):704-10. Available from: http://www.scielo.br/pdf/rsp/v41n5/5965. possibilitem acessar o seu mundo, a dinâmica utilizada para organizar as demandas diárias e, ainda, o que direciona as ações de seus membros, ou melhor, os significados atribuídos por eles frente à situação que estão vivendo. A avaliação estrutural é um recurso simples porém eficaz e permite identificar os membros, conhecer as relações intra e extra-familiares que podem estar envolvidas diretamente no cuidado.

A análise efetuada direciona os caminhos que 0 profissional de saúde tem a seguir. Entretanto, é preciso conduzir os familiares tendo como premissa o respeito às opções e às decisões por eles tomadas, pois o mundo de significados é próprio de cada família, embora contenha elementos do contexto em que está inserida.

Iniciar e manter a amamentação conforme é preconizado pode ser um prazer, mas também pode ser um momento difícil e até de sofrimento para aqueles que vivem a expectativa e a realização desse cuidado. Dada a complexidade de fatores que incidem sobre o ato de aleitar, a família, por meio da convivência, das atitudes favoráveis e de luta conjunta, pode trazer influências no processo da amamentação. Trabalhar com famílias coloca o profissional em contato com um vasto conjunto de significados que, nem sempre são compreensíveis. É preciso estar junto e considerar as condições físicas, emocionais, econômicas e de suporte para o momento vivido.

Nas famílias assistidas, a amamentação exclusiva, no momento da alta hospitalar e ambulatorial, foi possível, paralelamente às ações assistenciais, pelo método empregado - a avaliação estrutural e o diagnóstico das condições dos familiares -, bem como pela condição de suporte encontrada. É possível realizar essas intervenções na família quando a estrutura familiar e as relações e as interações entre seus membros são conhecidas. O diagnóstico pode indicar os pontos vulneráveis que podem ser trabalhados pela equipe de saúde, além de possibilitar a adequação do cuidado e dos recursos a serem utilizados para o atendimento às necessidades dos familiares.

3. Tronchin DRM, Tsunechiro MA. Cuidar e conviver com o filho prematuro: experiência do pai. Rev Lat Am Enfermagem [Internet]. 2006 [cited 2011 set 30];14(1):93-101. Available from: http://www.scielo.br/pdf/rlae/v14n1/v14n1a13.pdf.

4. Sales CA, Alves NB, Vrecchi MR, Fernandes J. Concepções das mães sobre os filhos prematuros em UTI. Rev Bras Enferm [Internet]. 2006 [cited 2011 set 30];59(1):20-4. Available from: http://www.scielo.br/pdf/reben/v59n1/a04v59n1.pdf.

5. Monteiro MAA, Pinheiro AKB, Souza AMA. Vivência de puérperas com filhos recém-nascidos hospitalizados. Esc. Anna Nery [Internet]. 2007 [cited 2011 set 30];11(2):276-82. 
http://www.scielo.br/pdf/ean/v11n2/v11n2a14.pdf.

6. Pacheco STA, Cabral IE. Alimentação do bebê de baixo peso no domicílio: enfrentamentos da família e desafios para a enfermagem. Esc. Anna Nery [Internet]. 2011 [cited 2011 set 30];15(2):314-22. Available from: http://www.scielo.br/pdf/ean/v15n2/v15n2a14.pdf.

7. Pinto JP, Ribeiro CA, Pettengill MM, Balieiro MMFG. Cuidado centrado na família e sua aplicação na enfermagem pediátrica. Rev Bras Enferm [Internet]. 2010 [cited 2011 set 30];63(1):1325. Available from: http://www.scielo.br/pdf/reben/v63n1/v63n1a22.pdf.

8. Teixeira MA, Nitschke RG. Modelo de cuidar em enfermagem junto às mulheres - avós e sua família no cotidiano do processo de amamentação. Texto Contexto Enferm [Internet]. 2008 [cited 2011 set 30];17(1):183-91. Available from: http://www.scielo.br/pdf/tce/v17n1/21.pdf.

9. Braga DF, Machado MMT, Bosi MLM. Amamentação exclusiva de recém-nascidos prematuros: percepções e experiências de lactantes usuárias de um serviço público especializado. Rev. Nutr. [Internet]. 2008 [cited 2011 set 30];21(3):293-302. Available from:

http://www.scielo.br/pdf/rn/v21n3/a04v21n3.pdf.

10. Wright LM, Leahey M. Enfermeira e famílias. Um guia para avaliação e intervenção na família. 4th ed. São Paulo: Roca; 2008.

11. Carvalho VD, Borges LO; Rêgo DP. Interacionismo simbólico: origens, pressupostos e contribuições aos estudos em Psicologia Social. Psicol. cienc. prof. [Internet]. 2010 [cited 2011 set 30];30(1):146-61. Available from: http://pepsic.bvsalud.org/pdf/pcp/v30n1/v30n1a11.pdf.

12. Charon, JM. Symbolic interacionism: an introduction, na interpretation, an integration. 3rd ed. Englewood Cliffs. PrenticeHall; 1989.

13. Marques ES, Cotta RMM, Magalhães KA, Sant'Ana LFR, Gomes, AP, Siqueira-Batista R. A influência da rede social da nutriz no aleitamento materno: o papel estratégico dos familiares e dos profissionais de saúde. Cien Saude Colet [Internet]. 2010 [cited 2011 set 30];15 Suppl 1:1391-400. Available from: http://www.scielo.br/pdf/csc/v15s1/049.pdf.

14. Teixeira MA, Nitschke RG, Silva LWS. A prática da amamentação no cotidiano familiar - um contexto intergeracional: influência das mulheres-avós. Revista Temática Kairós Gerontologia [Internet]. 2011 [cited 2011 set 30];14(3):205-21. Available from: http://revistas.pucsp.br/index.php/kairos/article/viewFile/6501/4713. 15. McCarter-Spaulding D. Is breastfeeding fair? Tensions in feminist perspectives on breastfeeding and the family. J Hum Lact. $2008 ; 24(2): 206-12$.

16. O'Brien M, Buikstra E, Falon T, Hegney D. Exploring the influence of psychological factors on breastfeeding duration. Phase 1: perceptions of mothers and clinicians. J Hum Lact. 2009;25(1):55-63.

17. Ângelo M. Cultura e cuidado da família. In: Nakamura E, Martin D, Santos JFQ. Antropologia para enfermagem. São Paulo: Manole; 2009. p. 82-99.

Artigo recebido em 30.07.2010.

Aprovado para publicação em 13.09.2011.

Artigo publicado em 30.09.2011. 